\title{
El Consulado de Comercio de Buenos Aires y la diputación por Santa Fe en torno al Informe Larramendi (1795). Normativa, gobernabilidad e Ilustración durante el siglo XVIII rioplatense
}

\author{
por \\ Adriana N. Milano ${ }^{1}$ \\ Universidad Nacional de Rosario, Argentina
}

En el marco de las reformas borbónicas implementadas por la Monarquía Hispánica para recuperar su antiguo esplendor, los consulados de comercio en América fueron instrumentos fundamentales en un nuevo reordenamiento. En este trabajo se analiza al consulado de comercio de Buenos Aires en relación a una de sus diputaciones, la santafesina, a propósito de un escrito conocido como el Informe Larramendi de 1795. El análisis evidencia la importancia de este documento como expresión de tensiones y disconformidades que enfrentaban a las elites santafesina y bonaerense; demostrando que el Consulado ponía a la luz problemáticas que iban más allá de las previstas por la Corona y que denuncian, en última instancia, rivalidades con Buenos Aires que se profundizarian en el siglo siguiente a partir de las guerras de Revolución.

Palabras Clave: Ilustración; Río de la Plata; gobernabilidad; reformas borbónicas; diputaciones.

Cómo Citar Este Artículo / Citation: Milano, Adriana N., "El Consulado de Comercio de Buenos Aires y la diputación por Santa Fe en torno al Informe Larramendi (1795). Normativa, gobernabilidad e Ilustración durante el siglo XVIII rioplatense", Revista de Indias, LXXXI/283 (Madrid, 2021): 729-764. https://doi.org/10.3989/revindias.2021.021.

\footnotetext{
${ }^{1}$ adria_milano@yahoo.com.ar, ORCID iD: https://orcid.org/0000-0002-6287-1712
} de uso y distribución Creative Commons Reconocimiento 4.0 Internacional (CC BY 4.0). 


\section{INTRODUCCIÓN}

En el transcurso del siglo XVIII las reflexiones acerca de la Monarquía Hispánica profundizaron sobre la idea y necesidad de recuperar su antiguo esplendor que remitía, principalmente, a la valoración del comercio y a su proyección imperial. José María Portillo Valdés planteó la existencia de un condicionante nacional en la Ilustración española que sometió a crítica profunda lo que entendía como «fundamentos periclitados» de los dominios extensos que conservaba. Dichas disquisiciones se enmarcaron en los debates ilustrados sobre España y su pertenencia al espacio literario europeo que estimulaba el pensamiento hispano de las últimas décadas del siglo. Un periodo durante el cual la Monarquía buscaba además de manera más intensa hallar la vía que le permitiera configurarse como imperio ${ }^{2}$. Consecuentemente, una nueva política guiaba a la reflexión económica y el «espíritu del comercio», convertido por Montesquieu en el «dulce comercio», reemplazaba al interés por la conquista como objetivo prioritario ${ }^{3}$.

Jesús Astigarraga analizó la necesidad, en tal contexto, de reordenar el amplio espacio de la Monarquía que surgía de manera explícita de la documentación oficial. Tal fue el caso de una consulta ministerial efectuada al rey en 1765 sobre el comercio interior y exterior de España con sus provincias y colonias americanas. La idea imperante era que en Indias se estaba materializando de modo imperceptible la independencia de sus vasallos por poseer «dentro de sus países lo necesario», con lo cual «será difícil mantenerlos dependientes sin la mutua comunicación de frutos y efectos». Esta sentencia manifestaba, como señaló Astigarraba, la preocupación creciente sobre el futuro de los territorios transatlánticos a partir del comienzo del reinado de Carlos III. La consulta elaborada por los ministros encargados de estudiar el fuerte atraso del comercio español sirvió, incluso, de posterior guía para el ciclo del comercio libre que signó las reformas dirigidas desde la metrópoli para remediarlo ${ }^{4}$.

Por otra parte, desde el comienzo de la Guerra de Sucesión en 1700 la guerra se convertía en una preocupación persistente para la Monarquía. Como analizaran Allan Kuethe y Kenneth Andrien, reforma y guerra desarrollarían a partir de ese momento una relación simbiótica en el mundo hispano atlántico ${ }^{5}$. Ordenar se tornaba imperioso. En particular para los dominios americanos, una

\footnotetext{
2 Portillo Valdés, 2018: 61-62.

3 Usoz, 2011: 11-46.

${ }^{4}$ Astigarraga, 2013: 760-761. La lectura del trabajo ilustra la corriente de críticas sobre los modos de gestionar el poder desde el reinado de Felipe V.

${ }^{5}$ Kuethe y Andrien, 2014: 1-31.
} 
serie de medidas comenzaron a implementarse para el reordenamiento, mejora y control de la gobernabilidad de los territorios. Entre las disposiciones, la erección de nuevos consulados de comercio fue una política institucional clave del período. Con un reordenamiento adecuado, los dominios americanos de ultramar, como engranajes de un nuevo impulso comercial, contribuirían a las modificaciones positivas esperadas a nivel de la Monarquía en su conjunto. En ese marco, los consulados de comercio americanos se convirtieron en instituciones fundamentales para ordenar e impulsar el comercio además de la industria y la agricultura; dirimir en conflictos comerciales locales, ejercer funciones pedagógicas a la manera de las Sociedades Económicas de Amigos del País en la Península, contribuir a las necesidades financieras de la Corona a raíz de los conflictos bélicos y actuar como espacio de sociabilidad de las elites de cada lugar donde se establecieron ${ }^{6}$. No obstante, no debe concluirse con ligereza que las instituciones consulares fuesen reflejo acabado de Ilustración e ideas modernas. También ha sido demostrada su persistencia como instituciones corporativas en defensa de intereses de los núcleos comerciantes, con costumbres, reglas e ideas propias de un contexto político de Antiguo Régimen ${ }^{7}$.

Hasta la decisión de erección de nuevos consulados en América a partir de la segunda mitad del siglo XVIII, solo habían operado dos: el de México y el de Lima, creados en 1594 y 1613, respectivamente. Entre 1793 y 1795 la corona estableció instituciones similares en Caracas, Guatemala, La Habana, Chile, Cartagena, Guadalajara y Veracruz. El consulado de comercio de Buenos Aires fue consecuencia de igual tendencia siendo erigido por Real Cédula de Carlos IV el 30 de enero de $1794^{8}$. Como en todos los casos, el consulado bonaerense debía proteger el intercambio mercantil y decidir sobre pleitos comerciales de modo breve y sumario. La decisión real para su creación había sido tomada luego de evaluar un informe presentado por el «cuerpo de comerciantes» de Buenos Aires con el aval del virrey Arredondo?.

${ }^{6}$ Grieco, 2014. Cruz Barney, 2002: 157-168.

${ }^{7}$ Como señalara Antonio Ibarra los consulados, resultados del impulso reformista, podían ser herederos de una dualidad que los ataba a la tradición, aunque pretendían llegar a ser instrumentos de la modernidad borbónica e impulsores del comercio libre. Tal fue el caso del consulado de comercio de Guadalajara, entre lo corporativo y la modernidad institucional, en una época de prosperidad económica que lo convirtió en una institución clave, donde sus miembros combinaron la lealtad imperial y la tradición con actitudes modernizadoras, aunque limitadas, para el fomento de una cultura económica de mercado. Ibarra, 2003: 310-312. Un análisis más exhaustivo en Ibarra, 2017.

8 Souto Mantecón, 1990: 227-250.

9 Real cédula de erección del Consulado de Buenos Aires, 30 de enero de 1794, Consulado de Buenos Aires, Antecedentes-Actas-Documentos, I, 1785-1795, Archivo General de la 
Dentro del Consulado correspondía a la Junta de Gobierno proteger y fomentar el comercio, promover el avance de la agricultura, la mejora de los cultivos, de los beneficios de los puertos, la introducción de máquinas y herramientas provechosas, la facilidad de la circulación interior y de todo aquello que pareciere conducente al mayor aumento y extensión de todos los ramos vinculados con el cultivo y el tráfico. Para ello, debía notificarse del estado de las provincias de su distrito recabando información por intermedio de diputaciones que debían crearse en los enclaves más convenientes. La Junta también podía recurrir a otras personas para el pedido de informes, y los resultados de las indagaciones dignos de «real noticia» debía notificarlos al virrey, proponiendo «las providencias que creyera necesarias para el beneficio de la agricultura, industria y comercio del país» ${ }^{10}$.

La erección del Consulado y el establecimiento de diputaciones significaron, además, cambios fundamentales en la administración de la justicia mercantil que desde ese momento dejó de pertenecer a la órbita de la justicia ordinaria y permitió agilizar la tramitación de los pleitos mercantiles incrementados a partir del aumento en la actividad comercial tras la sanción del Reglamento de Libre Comercio de $1778^{11}$. Por otra parte, es necesario remarcar el rol de intermediación del consulado bonaerense, al igual que los restantes de América, para conseguir donaciones y préstamos que aportaran al financiamiento de los gastos de guerra en Europa ${ }^{12}$.

En términos territoriales, la jurisdicción del consulado de Buenos Aires abarcaba todo el Virreinato del Río de la Plata, aunque, para un mejor funcionamiento, la Corona estableció la opción de las diputaciones que se considerasen necesarias para los puertos o lugares de mayor actividad comercial. Respecto del funcionamiento del Consulado como tribunal de justicia, los diputados estaban habilitados en su jurisdicción para actuar en los pleitos mercantiles que allí se presentaran. Los diputados conocían y determinaban sobre las causas entabladas, pero siempre en conjunto con dos colegas que debían escoger entre aquellos que contasen con iguales prescripciones a las dispuestas para el cargo de decano de la Audiencia; sumado a la asistencia del escribano del cabildo u otro acreditado. El consulado sugería dónde convenía nombrar diputados, aunque la decisión era firmada por el virrey. Es de destacar que para los lugares («pueblos» según la letra de la Real Cédula) sin diputaciones, los jueces ordi-

Nación Argentina, Buenos Aires, en adelante AGNA, Kraft ltda., Buenos Aires, 1936, Apéndice, lámina II.

10 Ibidem: lámina XVI-XVII.

11 Bistué y Acevedo, 2015: 363.

12 Kraselsky, 2011. Torres Sánchez, 2013: 13-129. 
narios suplantaban al consulado y a los diputados para que los demandantes pudiesen recurrir a ellos de resultarles conveniente ${ }^{13}$.

En ese contexto, se establecería la diputación por Santa Fe, una de las principales ciudades del Litoral y punto estratégico para la circulación mercantil.

El objetivo de este trabajo es analizar el Informe Larramendi como documento que condensa, a fines del siglo XVIII, la situación de vulnerabilidad, inequidad y decadencia que los santafesinos percibían frente a Buenos Aires. Una percepción que no resulta menor por provenir de vecinos que intentaban mantener su posición en los circuitos económicos que estaban en plena reorientación atlántica y manejaban el poder político de su ciudad. Un grupo de santafesinos cuyo pedido evidencia un descontento con la elite bonaerense que se profundizaría en el siglo siguiente, con agudos problemas que dificultarían la gobernabilidad desde Buenos Aires a partir del quiebre del orden virreinal ${ }^{14}$.

\section{LA DIPUTACIÓN SANTAFESINA}

En la segunda sesión del consulado de Buenos Aires, el 4 de junio de 1794, el primer tema tratado en función del mandato de la cédula de erección fue la propuesta de ciudades, puertos y villas donde convenía designar diputados para mejor cumplimiento de los objetivos previstos para la institución por la política borbónica. Era imperioso definir cuáles debían ser los puntos nodales hacia los que se extendería la gestión del Consulado, impulsando una comunicación más estrecha con las jurisdicciones de dichas diputaciones y su comercio local. Las ciudades elegidas fueron Montevideo, Corrientes, Paraguay, Córdoba, Mendoza, San Juan del Pico, Santiago del Estero, San Miguel de Tucumán, Salta, Jujuy, Chuquisaca, La Paz, Cochabamba, Oruro, Potosí y Santa Fe. El virrey Nicolás de Arredondo, conforme al artículo 10 de la Real Cédula de erección, manifestó su acuerdo y disposición para el nombramiento de los diputados, conocidos ya los nombres para los demás cargos, con recepción de informes con sugerencias de los gobernadores intendentes y de

${ }^{13}$ Real cédula de erección del Consulado de Buenos Aires, 30 de enero de 1794, Consulado de Buenos Aires, Antecedentes-Actas-Documentos, I, 1785-1795, AGNA, Kraft ltda., Buenos Aires, 1936, Apéndice, lámina IX y X.

14 Para iniciar un recorrido crítico sobre el concepto de gobernabilidad, su aplicabilidad o no al siglo XVIII y las transformaciones a partir del siglo siguiente sugiero Pagden, 1997: 137-164. Específico para la gobernabilidad desde las guerras de Revolución del siglo XIX: Ternavasio, 2007 y Verdo, 2009: 17-43. 
los subdelegados de los mismos pueblos, puertos y villas ${ }^{15}$. La totalidad de los primeros cargos de toda la institución consular a partir de 1794 (cónsul primero y segundo, prior, teniente de prior, síndico, secretario, contador, nueve consiliarios, dos tenientes de consiliarios) figuraban en una lista anexa a la misma cédula de erección, para que el organismo pudiese funcionar de inmediato. Luego de dos años se preveía la realización de elecciones por votación de electores para el reemplazo paulatino según los cargos. Los electores debían surgir de una «junta general del comercio» convocada por el prior y los cónsules para efectuar el sorteo los candidatos ${ }^{16}$. La administración de justicia estaba a cargo del tribunal del Consulado, compuesto sólo por el prior y dos cónsules ${ }^{17}$. Respecto de los diputados, estaban habilitados para actuar en los pleitos mercantiles de su jurisdicción y al igual que aquellos, podían recusarse con causa legítima y probada. Asimismo, contaban con derecho de participar en relación a las funciones vinculadas con la Junta de gobierno que operaba dentro del Consulado ${ }^{18}$. Como los miembros del Tribunal o los jueces de alzada, los diputados tenían facultad de fijar multas o penas pecuniarias y debían cumplir las mismas condiciones que el prior y los cónsules para su designación. El período de ejercicio de funciones era también bienal. Algunas de las características previstas para ser designado, y el hecho de que Candioti fuese electo como tal, dan prueba de su conocida posición de prestigio como santafesino y rioplatense: debían ser hombres de caudal conocido, de buena opinión y fama, prácticos e inteligentes en las materias de $\operatorname{comercio}^{19}$. Para las elecciones que siguieran al primer bienio se seguirían las propuestas del cónsul ingresante y el saliente en funciones. Cada uno debía proponer un diputado para cada lugar. Efectuada la elección el decano debía notificar a los «corregidores o alcaldes de los pueblos» para que otorgaran la posesión del

15 Acta del 4/06/1794, Consulado de Buenos Aires, Antecedentes-Actas-Documentos, I, 1785-1795, AGNA, Kraft ltda., Buenos Aires, 1936, 215-216.

16 Real cédula de erección del Consulado de Buenos Aires, 30 de enero de 1794, Consulado de Buenos Aires, Antecedentes-Actas-Documentos, I, 1785-1795, AGNA, Kraft ltda., Buenos Aires, 1936, Apéndice, lámina XXXI-XXXIV.

17 Ibidem, lámina IV.

18 Ibidem, lámina XII.

${ }_{19}$ El artículo 46 de la cédula establecía que el prior, cónsules consiliarios y síndicos debían ser naturales de los dominios de la Monarquía, mayores de edad, hombres de caudal conocido, de buena opinión y fama, prácticos e inteligentes en las materias de comercio; pero no debían ser parientes entre sí hasta el tercer grado de consanguinidad o de afinidad, ni socios de una misma compañía, ni mercaderes de tienda abierta. Real cédula de erección del Consulado de Buenos Aires, 30 de enero de 1794, Consulado de Buenos Aires, AntecedentesActas-Documentos, I, 1785-1795, AGNA, Kraft ltda., Buenos Aires, 1936, Apéndice, lámina XXXV. 
cargo a los nuevos diputados, tomándoles el mismo juramento dispuesto para el prior y los cónsules ${ }^{20}$.

Con estos lineamientos, el 24 de noviembre de 1794 quedó formalmente establecida la diputación por Santa $\mathrm{Fe}$ con su primer diputado, Francisco Antonio Candioti ${ }^{21}$.

Al igual que se ha demostrado para otros espacios, la diputación de Santa Fe representaba a grupos comerciantes que no siempre mantuvieron relaciones armónicas con sus pares del grupo consular bonaerense a consecuencia de sus decisiones ${ }^{22}$. Las tensiones que podían derivar de las decisiones tomadas desde Buenos Aires no sólo provinieron de Santa Fe, las diputaciones de Montevideo y de Potosí fueron otras en desacuerdo con el grupo bonaerense sobre todo por los gravámenes comerciales que lograron imponer al resto de la comunidad en beneficio propio y de la Monarquía - y que culminaría luego en derivaciones políticas, además de económicas ${ }^{23}$.

Conviene en primer lugar mencionar las características, en términos de circulación mercantil, del contexto rioplatense considerado. Fernando Jumar identificó en el período 1714-1778 la configuración de un espacio económico delimitado por tres complejos portuarios: uno de agua (el rioplatense) y dos secos (el cuyano y el salto-jujeño). El rioplatense, otrora parte del espacio peruano, se veía polarizado por la región Río de la Plata (con lógicas diferentes a las identificadas por Assadourian para el espacio más amplio), aunque la corona no intentaba aún de forzar prioritariamente la reorientación del Alto Perú hacia el Atlántico por este complejo. Sin embargo, el Río de la Plata atraía como gran mercado de consumo y se veía beneficiado por los efectos del comercio de ultramar en los mercados regionales que comenzaron a preferir este circuito, más conveniente en tiempos y costos en comparación con otros. Tales circunstancias hicieron que el complejo portuario rioplatense concentrara con el tiempo la salida de rentas hacia ultramar ${ }^{24}$.

Al norte de Buenos Aires, Santa Fe contaba con las posibilidades que le brindaba su posición geográfica. Su condición natural de «bisagra» (por su ubicación estratégica ribereña que la conectaban con el Paraguay y su carácter de acceso a los caminos interiores que conducían a Potosí), la convirtieron

${ }^{20}$ Ibidem, lámina XXXVII.

${ }^{21}$ Comunicación al Consulado, 24/11/1794, Consulado de Buenos Aires, AntecedentesActas-Documentos, I, 1785-1795, AGNA, Kraft 1tda., Buenos Aires, 1936, 262.

22 Para otros casos americanos de relación de los consulados con sus diputaciones y desavenencias entre elites consulares y regionales véanse: Mazzeo, 2012. Cruz Barney, 2007: 295-325.

${ }^{23}$ Kraselsky, 2016: 3-35.

${ }^{24}$ Jumar, 2016: 223. Assadourian, 1983. 
en un nudo conector de crecimiento comercial terrestre y fluvial hacia el interior del espacio peruano, con una estructura compleja y diversificada durante el siglo XVIII, beneficiada por otra parte por lo que se denominó el «privilegio de puerto preciso» (obligatoriedad de que todos los buques desde Paraguay desembarcaran en Santa Fe); aunque este fuera finalmente retirado en 1780 por influencia de Buenos Aires ${ }^{25}$. La historiografía ha coincidido sobre la vigencia acotada del privilegio Real de «puerto preciso» entre 1740 y 1780 . Su posición natural de puerto indispensable creó las condiciones para la expansión de la ciudad y la aparición de un sector mercantil relevante que promovió la declaración formal del privilegio ante la corona. Desde 1726, una serie de disposiciones pretendieron ratificar ese estatus desde lo normativo y fiscal, situación que generó un largo conflicto que representó la disputa entre dos proyectos locales (de la elite bonaerense frente a la santafesina) de configuración espacial. Ello en el marco de la política de transformación sin precedentes promovida por España durante el siglo XVIII, donde la acción de los agentes jugó un rol vital: Santa Fe y Buenos Aires pensaban su futuro en base a su experiencia pasada y una serie de lazos e intereses mostraban una lógica social compleja más allá de las meras explicaciones económicas ${ }^{26}$.

El privilegio santafesino de puerto preciso fue así gestionado por uno de esos miembros en ascenso de la elite de la ciudad, Juan José de Lacoizqueta, perteneciente a una familia presente en el manejo político de la ciudad, emparentada a los Candioti y los Larramendi considerados en este trabajo ${ }^{27}$. Con su intervención, los vecinos fueron representados en 1737 ante la Audiencia de Charcas y el tribunal declaró formalmente a la ciudad «puerto preciso del Paraguay» en 1739, ratificado por la Corona por Real Cédula de 1743. El beneficio permaneció hasta 1780. El mencionado Lacoizqueta, encargado de las gestiones, financió toda la tramitación y fue nombrado recaudador de los arbitrios derivados. En Buenos Aires la imposición no se recibió con agrado. Se decía que era una prebenda real que transmutaba en beneficios comerciales para un pequeño grupo santafesino, el mismo que controlaba el Cabildo y manejaba la información necesaria para obtener ventajas económicas derivadas de ese monopolio ${ }^{28}$.

Si bien el privilegio fue ratificado por Real Cédula en 1743 y luego en 1756, la oposición bonaerense, que al fin triunfó, hizo que Santa Fe debiera comenzar un proceso de reacomodamiento hacia el Atlántico estrechando

\footnotetext{
25 Tarragó y Areces, 1999: 79-98.

26 Mayores detalles en Tarragó, 2012: 272.

27 Damianovich, 1991: 37-70.

28 Tarragó, 2012: 281.
} 
vínculos mercantiles con Buenos Aires a partir de la supresión del beneficio, Los comerciantes de yerba fueron mutando hacia la combinación de antiguos rubros con la producción y venta de cueros y mulas ${ }^{29}$.

Hasta la dislocación final en el circuito de intercambios provocada por las guerras de revolución a partir 1810, Santa Fe participó en la comunicación entre los nodos principales de actividad, a pesar de la situación negativa que significó para buena parte de la población la supresión del puerto preciso. Asunción del Paraguay se conectaba con Buenos Aires pasando por Santa Fe y otras líneas imaginarias podían trazarse desde Santa Fe hacia Córdoba, el Alto Perú, Chile y el este con destino a la Banda Oriental. La ciudad de Santa Fe creció durante los siglos XVII y XVIII a pesar de los inconvenientes y desaceleraciones que pudieran provocar inundaciones, incursiones contra los indios, sequías o invasión de langostas. El carácter de la ciudad como centro redistributivo de yerba mate, azúcar, tabaco y miel del Paraguay desde el siglo XVII, promovió el establecimiento de almacenes, organización de caravanas, arreos de animales, demanda de medios para el financiamiento, de fletes, producción agrícola para el abastecimiento y la incorporación complementaria de géneros y otros efectos de Castilla para satisfacer las necesidades de consumo de la ciudad y otros núcleos a ella vinculados ${ }^{30}$.

Como se mencionará, en Santa Fe comenzó a operar una transición hacia otro tipo de economía a partir de 1750. La transformación tendía a preservar la fortuna que como empresarios (además de cabildantes, procuradores y diputados por Santa Fe) había logrado un grupo de vecinos de la ciudad. El sector ganadero, productor de cueros, logró empuje frente a la pérdida de interés por el negocio yerbatero. Se combinaba producción rural con su comercialización. Fueron figuras como Manuel Ignacio, Diez de Andino, José Teodoro de Larramendi y Francisco Antonio Candioti, las que cobraron protagonismo. Estos empresarios, estancieros, productores y comerciantes de cueros y mulas reorientaron sus actividades más allá de los efectos del puerto preciso cancelado en 1780 . No obstante, la nostalgia por ese beneficio impulsó el informe de José Teodoro de Larramendi en 1795 aunque hombres como él no dejaron de readaptarse al nuevo proceso de reconfiguración que se vivía ${ }^{31}$.

Ese conjunto de hombres, representaban a las familias santafesinas prominentes del siglo XVIII. Según investigaciones recientes, fue en función de pujas por el poder local durante dicho siglo que las principales familias san-

\footnotetext{
29 Tarragó, 1995-96: 217-238.

${ }^{30}$ Una visión del conjunto del espacio se aprecia en Garavaglia, 2008.

31 Tarragó, 2012: 284.
} 
tafesinas - unas veintiocho en total- lideraron el manejo de instituciones como el cabildo o las cofradías, de las tierras y los circuitos económicos. Ante todo, sus miembros eran comerciantes y hacendados, emparentados entre sí por una fuerte tendencia a los matrimonios endogámicos ${ }^{32}$.

Ese grupo de personas provenía de una oleada de asentamiento tardío en la ciudad, en comparación con los vecinos «beneméritos» descendientes de conquistadores. La mayoría de ellos habían arribado durante el mismo siglo XVIII o finales del anterior. La particularidad de su lugar de origen no es un dato menor. Son conocidas las investigaciones, a propósito de los mercaderes españoles, acerca de la habilidad de los comerciantes del norte de la península ibérica para proyectarse por Europa y América en el marco de las reformas borbónicas. En el Río de la Plata — donde se estableció un virreinato en 1776 con la ruptura de su antigua subordinación al Perú- los mercaderes del Cantábrico y Cataluña, sobre todo, vieron un nuevo espacio de oportunidades que aprovecharon con habilidad ${ }^{33}$. El rol de los vasco-navarros dentro de la monarquía hispánica destaca no sólo en relación al siglo XVIII, sino durante todo el periodo moderno ${ }^{34}$. Para el Río de la Plata varios casos ilustran la trayectoria de los españoles del norte en su expansión atlántica ${ }^{35}$. Susan Socolow es el referente historiográfico acerca de las trayectorias de grupos comerciantes que se expandieron en el espacio rioplatense; estudio complementado por análisis posteriores sobre vizcaínos con influencia en el Consulado de Comercio de Buenos Aires ${ }^{36}$. En Santa Fe, se corrobora igual presencia de peninsulares del norte en los grupos de la elite y, en el caso bajo análisis los Larramendi emparentados luego a los Candioti desde el año 1800, son un ejemplo. Originarios del norte de la península, los Larramendi contaban con familiares de igual origen asentados en distintos puntos del virreinato del Río de la Plata, sitios por otra parte estratégicos para la circulación comercial ${ }^{37}$.

32 Desde inicios del XVIII la redistribución del poder local benefició a los Echagüe y Andía, Vera Mujica y Maciel. Entre 1720 y 1750, se sumaron al núcleo dominante los Candioti, Larramendi, De Iriondo y Diez de Andino. En la segunda mitad del siglo el círculo se completó con los Aldao, Crespo, Iturraspe, Freire y Lassaga. Cervera, 2004: 5-7.

${ }_{33}$ Halperin Donghi, 1985: 56.

${ }^{34}$ Véase: Imízcoz Beunza, 2008: 89-119. Respecto del siglo XVIII en particular: Guerrero Elecalde, 2012.

35 Emblemático en ese sentido el caso de la familia Zavala, oriunda de Viscaya, quien logró ubicar en 1717 a uno de sus vástagos, Bruno Mauricio de Zavala, al mando de la gobernación de Buenos Aires, lo que indica la prosperidad de la red y la casa de los Zavala alcanzada dentro de la corte de Felipe V. Tarragó, 2010: 196.

${ }^{36}$ Guerrero Elecalde, 2012. Caula, 2011: 153-181.

${ }^{37}$ Los Larramendi contaban con contactos familiares y a la vez comerciales-políticos en ciudades como Tucumán, Córdoba, Santiago del Estero, La Rioja, entre otras. Milano, 2018: 213-246. 
Para estas familias de Santa Fe tardocolonial, como en tantos otros enclaves de la Monarquía, comerciar no era una esfera independiente y alejada de las restantes ${ }^{38}$. Los hombres dedicados al comercio encabezaban grupos familiares relacionados entre sí por lazos diversos que tejían las tramas del poder político y económico local, donde oeconomía, casa y padre de familia constituían una tríada que regulaba el funcionamiento colectivo ${ }^{39}$. Como planteara Bartolomé Clavero, entre los siglos XVI al XVIII la cultura cristiana fijaba los lineamientos del mundo social y reconocía en la gracia recíproca al elemento fundante de los intercambios, regulados por un sentimiento de amistad y de reconocimiento mutuo ${ }^{40}$. Estos valores, al igual la relación entre la ética, la oeconomía y la política para referir a las virtudes del hombre, del señor de la casa y del hombre de Estado como señaló Otto Brunner, se hallaban plenamente presentes en la mentalidad santafesina de la época, con la vinculación de la lógica del pater familias y del buen gobierno como discurso moral ${ }^{41}$.

Como sucedía en distintas ciudades modernas a ambos lados del Atlántico, los comerciantes santafesinos recorrían largas distancias por tierra, río y mar, lejos del modelo de mercader establecido en un lugar fijo con intercambios rutinarios $^{42}$. La matriz de intercambios se sustentaba en tramas de vínculos basados en el parentesco, la amistad, origen común o experiencias compartidas entre otras que articulaban la integración de los circuitos mercantiles que podía llegar, incluso, a escala imperial ${ }^{43}$. Por ello, las políticas de mejoras que pudiese implementar desde Buenos Aires el Consulado de Comercio con la gestión de los diputados santafesinos eran una oportunidad de crecimiento para la ciudad, al poder contar con una institución reformista e Ilustrada que derivara en beneficios al igual que otros consulados o las Sociedades Económicas de Amigos del País de la Península.

En ese enclave periférico de la Monarquía la realidad cotidiana del conjunto de comerciantes santafesinos los conducía a arbitrar los medios para superar la incertidumbre permanente de un contexto signado por los ataques de los indios, las sequías, el avance de las langostas sobre las cosechas y las decisiones tomadas en Buenos Aires que afectaban a la jurisdicción. La prin-

${ }^{38}$ Es vasta la bibliografía sobre América que corrobora tal aspecto. Un ejemplo clásico para el México borbónico (Brading, 1983).

39 Véase como ejemplo de las sociedades al sur del Virreinato del Perú: Zamora, 2017.

${ }^{40}$ Clavero, 1991.

${ }^{41}$ Brunner, 1976: 87-123.

42 Fernando Jumar identificó para el espacio portuario rioplatense tipos de comerciantes según el grado de arraigo al lugar de actuación desde los residentes hasta «golondrinas», con categorías intermedias. Jumar, 2011: 209.

${ }_{43}$ Caula, 2011: 155. Jumar, 2016: 166-259. 
cipal medida perjudicial para Santa Fe había sido sin duda la supresión del llamado «privilegio del puerto preciso». La desaparición de tal privilegio había resultado devastadora para buena parte de la población.

Francisco Antonio Candioti, primer diputado frente al Consulado, era un hacendado y hombre de negocios que representaba al mencionado sector comerciante de la ciudad de Santa Fe y ya contaba con experiencia en la intermediación frente a Buenos Aires. Con amplia participación en el circuito mercantil, Candioti efectuaba principalmente operaciones con ganado mular en el mercado salteño y peruano, al igual que hacia el Reino de Chile; además de pertenecer al núcleo de santafesinos que operaban en la ruta noreste hasta Asunción del Paraguay para el intercambio de yerba y efectos de Castilla ${ }^{44}$.

Respecto de su función como diputado frente al consulado de comercio de Buenos Aires, la actitud de Candioti estuvo alejada de lo esperado para un vecino de la élite. Susan Socolow demostró que el Consulado era signo de prestigio, espacio de sociabilidad y lugar donde se proyectaban tramas de relaciones políticas, económicas y sociales provenientes de otros ámbitos, como el $\mathrm{Cabildo}^{45}$. El propio secretario vitalicio de la institución, Manuel Belgrano, era hijo de uno de los principales mercaderes de la ciudad ${ }^{46}$. Las conclusiones de Socolow fueron ampliadas por estudios posteriores ${ }^{47}$. Comportamientos similares se detectaron para otros consulados americanos: pertenecer a un consulado de comercio era una aspiración para cualquier individuo de la élite ${ }^{48}$. Esto no sucedió con Candioti, quien además de priorizar sus negocios, desconfiaba de las posibilidades de lograr beneficios desde Buenos Aires ${ }^{49}$.

Candioti manifestó desde su nombramiento sus dudas frente a las posibilidades para Santa Fe que podían resultar de una diputación ${ }^{50}$. El desinterés no era infundado, años antes había fracasado frente a la intransigencia bonaerense. Durante 1781, en oportunidad de desempeñarse como alcalde de Santa Fe había intentado mejorar la situación santafesina de opresión por las con-

${ }^{44}$ Sobre Candioti: Cervera, 1942. Cornejo, 1979: 101-113. Romitti Acevedo, 2009: 513523. Milano, 2018: 3-530. Respecto al comercio entre Santa Fe y el Paraguay: Paredes, 2014: 66-80.

${ }^{45}$ Socolow, 1991: 205-226.

46 Gelman, 1996. Milano, 2019.

47 Jumar y Kraselsky, 2007: 31-58.

${ }^{48}$ Hernández García, 2013: 123-141. Del Valle Pavón, 2015: 149-171.

49 Candioti, 1960: 20.

${ }^{50}$ En febrero de 1795 consultó acerca de las posibilidades de ausentarse en sus funciones por motivos particulares. Archivo General de la Provincia de Santa Fe, Santa Fe, en adelante AGPSF, actas de Cabildo Santa Fe, en adelante ACSF, 27/04/1795, tomo XVI B, f. 306. 
tribuciones exigidas desde Buenos Aires y su fracaso lo había desalentado respecto de la actuación política. Al finalizar su mandato, Candioti reanudó la atención de sus estancias y los viajes comerciales hacia Salta y el Perú, convencido de que poco había logrado frente a las autoridades bonaerenses para mejorar la coyuntura desfavorable para Santa $\mathrm{Fe}^{51}$. La alternancia de Candioti entre la actividad política y la solicitud de retiro para atender cuestiones particulares se dio de manera reiterada entre 1781 y 1815 , año en que falleció. Lo mismo puede decirse de otro reconocido comerciante y hacendado santafesino, Francisco de Aldao, hermano político de Candioti quien si bien participó de modo contemporáneo con su cuñado en la vida política de la ciudad ejerciendo diferentes cargos. Aldao no dudaba en pedir eximición temporaria de sus funciones para atender sus negocios particulares, varios de ellos en conjunto con Candioti y José Teodoro de Larramendi, el autor del informe objeto de este trabajo y además amigo, socio y suegro de Candioti a partir de $1800^{52}$. Estos casos hacen pensar en cómo se veían estos sujetos en relación a Buenos Aires: desatender las propias actividades para intentar vanas negociaciones no pareciera ser la tendencia. Estas actitudes muestran la necesidad de revisar las hipótesis habituales acerca del comportamiento homogéneo de las elites hispanoamericanas; tanto las que refieren a su afán por participar de los consulados de comercio como así también aquellas sobre su mentalidad y patrones de conducta comunes en términos generales ${ }^{53}$.

Así entonces, frente a una experiencia negativa en el pasado ante Buenos Aires, para 1794, año de erección del Consulado, Candioti estaba lejos de aspirar a ser diputado. Combinaba la comercialización de ganado vacuno y mular, con la organización de arreos e invernadas hacia el norte encontrándose en plena actividad, situación que refrenda aquellas argumentaciones que plantearon el interés de comerciantes santafesinos de invertir esfuerzos, a partir de mediados del siglo XVIII, en el sector ganadero productor de cue$\operatorname{ros}^{54}$. Candioti es además un ejemplo de los vecinos que a pesar de la supresión del privilegio del puerto preciso de 1780 no habían visto afectada su capacidad de generación de negocios. De hecho, su giro comercial se hallaba en pleno desarrollo en conexión con las plazas mercantiles porteña, del mer-

51 Candioti, 1960: 29.

52 Milano, 2018: 93-247.

53 En este sentido es una variante a las nociones sobre las elites analizadas por Frédérique Langue, por ejemplo, si bien es cierto que Candioti respondía en muchos otros aspectos a lo postulado por la autora más allá del caso puntual de su actuación frente al Consulado. Langue, 1992: 123-139.

54 Tarragó, 1995-96: 217-238. 
cado norteño, Chile y de Asunción; además de zonas intermedias interconectadas con éstas ${ }^{55}$. Tanto Candioti como Larramendi mantuvieron actividad mercantil e invirtieron en tierras durante la segunda mitad del siglo XVIII a pesar de la crisis local. En ese sentido se acercaron al modelo de comerciantes mencionados por Halperin Donghi, aquellos que desde 1750 prosperaron en lo que denominó una creciente «ruralización» del espacio santafesino. Por cierto, Candioti fue citado como ejemplo por Halperin Donghi ${ }^{56}$.

No obstante casos particulares, fue en este contexto de supresión del privilegio de puerto preciso que la relación entre Santa Fe y Buenos Aires fue tornándose conflictiva.

\section{El INFORME LARRAMENDI}

Para 1794 las autoridades capitulares santafesinas consideraban que la situación de la ciudad había llegado a un punto crítico después de una década y media de deterioro comercial. Ante la coyuntura insostenible, el nuevo teniente de gobernador, Prudencio de Gastañaduy, convocó a los vecinos para pedir su apoyo frente a la indiferencia de Buenos Aires. Gastañaduy ofreció a Candioti una vez más el cargo de alcalde y éste se negó a menos que fuese obligado por decisión del pueblo. En esos días Manuel Belgrano asumía como secretario vitalicio del Real Tribunal del Consulado de Buenos Aires, situación que generó esperanza en las ciudades del interior ${ }^{57}$. Se presume que, ante la noticia, Candioti decidió realizar un viaje a Buenos Aires con la intención de mantener un diálogo conciliatorio y favorable para la ciudad de Santa Fe. Si bien existe constancia que cierta amistad unía ya a Candioti con Belgrano, en Santa Fe se creía sin embargo que el grupo de vecinos españoles designados para el Consulado - junto al secretario vitalicio - ofrecía pocas posibilidades futuras de responder a intereses ajenos a los de su grupo de pertenencia ${ }^{58}$.

El documento conocido como Informe Larramendi, fue confeccionado a instancias de la solicitud de información del Consulado en 1795. Ante la situación económica precaria que se denunciaba de la zona santafesina a partir de la supresión del puerto preciso luego de cuarenta años en que los productos paraguayos (yerba, tabaco y algodón) debían desembarcarse de manera

\footnotetext{
55 Milano, 2018: 153.

${ }^{56}$ Halperin Donghi, 1972: 32-40.

57 Candioti, 1960: 28.

58 Ibidem: 30.
} 
obligatoria en Santa Fe; el acentuado despoblamiento y la recaudación diezmada eran consecuencias lógicas que agravaban aún más el panorama futuro ${ }^{59}$.

La realidad santafesina tampoco pasó inadvertida en el discurso Ilustrado de Félix de Azara. Es sabido que el siglo XVIII significó en la península ibérica la puesta al día con los avances respecto del resto de Europa en el terreno de las modernas teorías: la geografía, botánica, astronomía, matemática y la organización de expediciones científicas permitieron a la corona utilizar estos saberes para fomentar, entre otros objetivos, el conocimiento de sus dominios de ultramar ${ }^{60}$. Tales experiencias fueron aprovechadas por la corona hispánica para promover el poblamiento y una mejor explotación de las tierras al sur de América, frente al contexto de amenaza portuguesa sobre la región y la expulsión de los miembros de la Compañía de Jesús. En tal sentido Azara, como funcionario borbónico, ingresó al Río de la Plata y su paso por Santa Fe mereció su atención al ser uno de sus intereses primordiales aportar al fomento de la utilidad pública ${ }^{61}$. En un viaje hacia Corrientes relataba cómo Santa Fe era «árbitra del comercio de Río arriba y de la conducción á otras partes. Los paraguayos se veían precisados á tomar la ley de los comerciantes de este pueblo que los tiranizaba». Después de la conclusión del privilegio de puerto preciso, decía Azara, «ya se empieza á conocer bastante que esta ciudad y su comercio va en decadencia» ${ }^{62}$. El juicio sobre la tiranía de los santafesinos deja entrever una postura de Azara no favorable hacia Santa Fe, quizá producto de opiniones recabadas de contemporáneos rioplatenses.

Para marzo de 1795, mes en que Candioti presentó el oficio del pedido del Consulado la coyuntura de la ciudad se veía agravada por un periodo prolongado de sequía ${ }^{63}$. El informe a confeccionar por requerimiento del Consulado debía detallar el estado al momento de la agricultura, del comercio y

59 Damianovich, 2010: 73. Para 1793 los ingresos de propios y arbitrios llegaron solamente a 256 pesos. Para los comerciantes de Perú y Chile resultaba mucho más barato sacar la yerba de Buenos Aires y Paraguay; los derechos de entrada y salida abonados en Buenos Aires eran menores con lo cual el tráfico vía Santa Fe no resultaba conveniente. Los derechos de entrada y salida eran menores en Buenos Aires y el cabildo de Santa Fe ve la necesidad de solicitar igualación de tasas para ambas ciudades. En ese contexto Larramendi, como procurador, fue comisionado con un informe en julio de 1795 para solicitar auxilio y medidas equitativas que revirtiesen la situación de la ciudad en pleno declive. El informe luego de varias páginas daba cuenta pormenorizada de las causas y medidas solicitadas en beneficio de la población santafesina. Cervera, 1907: 126.

${ }^{60}$ Fernández Sebastián, 1998: 347.

${ }^{61}$ Quarleri, 2011: 753-782.

62 De Azara, 1873: 21. Suárez y Tornay, 2003: 521-555. Martínez Martín, 1997: 167-192.

${ }^{63}$ AGPSF, ACSF, 23/03/1795, tomo XVI B, f. 300. 
de la industria, con propuestas para su fomento. Debían incluirse las innovaciones que se consideraran necesarias a partir de la orientación y consejo «de todos los vecinos de mejor consejo, sin despreciar el menor por la importancia y consecuencia de semejantes asuntos $\rangle^{64}$. La idea de participación de todos los vecinos se asemeja, aunque en menor escala, a las políticas Ilustradas desplegadas en el seno de las Sociedades Económicas de Amigos del País en la Península, donde se promovía la consideración de todo aquél que pudiese aportar con ideas innovadoras para el fomento de las actividades productivas ${ }^{65}$. En esto la política borbónica por intermedio del Consulado y las diputaciones, a falta de dichas Sociedades en América, fomentaba las iniciativas de exploración y pedagógicas que éstas últimas desempeñaban de modo mucho más organizado y amplio en España.

El informe fue preparado y presentado por José Teodoro Larramendi como procurador y síndico general en los primeros días del mes de julio. El texto agradecía el interés y disposición de la corona española por la región, manifestados en la decisión de erección de un Real Consulado y la solicitud de información por parte de la Junta; interpretado por las autoridades locales como uno de los primeros pasos para la promoción de los asuntos de la ciudad. Larramendi manifestaba su interés en contribuir a la búsqueda de innovaciones para el progreso. Es de remarcar que durante el siglo XVIII América mantuvo su acatamiento a la autoridad monárquica, aún en los casos de las reacciones causadas por el reformismo borbónico puesto que si bien éstas criticaban un mal gobierno, no cuestionaban la lealtad al rey ni el formar parte de la nación española; aunque el hecho de pertenecer sí les daba derechos a reclamar un trato más justo ${ }^{66}$. La posición de Larramendi coincide con esa actitud americana general y con la expresada contemporáneamente por Manuel Belgrano que como secretario vitalicio del Consulado y miembro de la élite comerciante, expresaba en las memorias consulares su acatamiento a la corona intentando aportar para el progreso general como vasallo «útil» y funcionario virreinal ${ }^{67}$.

Con esa intención, el escrito presentaba el panorama general de la ciudad; el estado del comercio, de la agricultura y de la industria para proponer, por

${ }^{64}$ Ibidem, f. 301.

${ }^{65}$ En las memorias de la Sociedad Matritense de Amigos del País abundan casos de nuevas técnicas o instrumentos presentados para el conocimiento general. Véase el ejemplo de una novedosa sembradora inventada por Josef Lucatelo en 1777: Real Sociedad Económica Matritense de Amigos del País, 1780: 9-15.

${ }^{66}$ Véanse las reflexiones sobre el movimiento comunero de 1781 en el Virreinato de Nueva Granada en Finestrad, 2000. Wasserman, 2015: 27. Palti, 2018: 125-156.

${ }^{67}$ Belgrano, 1797: 81. 
último, una serie de soluciones. El estado de la ciudad distaba de ser favorable. En términos poblacionales había un número aproximado de 4000 almas distribuido entre doce cuadras de sur a norte y seis de este a oeste. Se esperaba que unas sesenta familias abandonasen la ciudad al igual que lo hicieran otras sesenta anteriormente, desde la abolición del puerto preciso. De ese total de habitantes se estimaba que solo setenta correspondían a la clasificación de vecinos distinguidos. Al estado general de estancamiento se sumaba el deterioro en las construcciones donde solo podían relevarse ciento treinta y casas de tejas entre unas trescientas habitaciones de paja, junto a sesenta abandonadas y veinte completamente en ruinas ${ }^{68}$.

Larramendi se presentaba a sí mismo como hombre de reconocida experiencia: a su trayectoria como comerciante en Santa Fe, en la provincia de Paraguay, Córdoba y reino de Chile agregaba su conocimiento como vecino y descendiente de fundadores de la jurisdicción y de sus necesidades; a ello sumaba su deseo de aportar para el fomento de la zona como hombre público, actual síndico procurador y varios años antes juez de la ciudad ${ }^{69}$. Para fines del siglo XVIII no prevalecía aún la idea de nación que se impondría desde mediados del siglo siguiente, si bien existía consenso de que cierta homogeneidad en la población contribuía a una mejor gobernabilidad. El fundamento de la nación recaía todavía en el derecho divino o en la afirmación de pactos entre sus miembros como cuerpos colectivos o individuos. No existía el presupuesto de que sus miembros debieran compartir una identidad étnica o atributo distintivo ${ }^{70}$. En tal sentido, Larramendi apelaba a su calidad de «vecino» o "vecino del comercio de Santa Fe» como se manifestaba en los documentos públicos, fuesen escrituras públicas, expedientes civiles o actas del cabildo para referir a los sujetos residentes en la ciudad que poseían ante todo calidad de «comerciantes» e intervenían en la instancia documentada. Así se reconocía Larramendi: vecino y descendiente de fundadores ${ }^{71}$.

La situación era alarmante en general. En agricultura, la poca variedad en la producción de hortalizas y frutos, a pesar de las posibilidades ofrecidas por el suelo, acuciaba una actividad laxa, con descuido de las explotaciones que se destinaban al abasto de Santa Fe, Tucumán y Cuyo. Las manufacturas y la industria presentaban semejante estancamiento. La cría especializada de ganado ovino, vacuno y mular se reducía a unas diez o doce haciendas. La oferta de productos locales se limitaba a umbrales, postes y estacas de made-

\footnotetext{
68 “Informe del procurador Larramendi”, apéndice XXVII, Cervera, 1907: 129.

${ }^{69}$ Ibidem: 128.

70 Wasserman, 2015: 26.

71 Sobre la significación en dicho contexto del término «vecino»: Cansanello, 2008: 19-34.
} 
ra; aún en oficios habituales como la herrería, zapatería o carpintería era marcada la escasez de personas dedicadas a estas tareas. La confección de paños de lana y lienzos tampoco estaba desarrollada: la producción recaía en mujeres de escasos recursos y se destinaba al consumo familiar. En esto Larramendi coincidía con lo expresado por Manuel Belgrano en sus recomendaciones al Consulado, para lo cual preveía planes de acción concretos ${ }^{72}$. El comercio abarcaba un bajo número de cueros transportados a Buenos Aires; sacas de «algunas puntillas pequeñas de mulas» arreadas anualmente al Perú. El tráfico mercantil involucraba también unas pocas cantidades de garbanzos y naranjas hacia Buenos Aires y Córdoba ${ }^{73}$.

Para el Procurador, las causas de tan empobrecida situación, más allá de los inconvenientes climáticos y de la escasa población, se encontraban en la abolición del puerto preciso, la ubicación de la ciudad, el gusto de la población y la desigualdad de la jurisdicción frente a lo que describía como «gravámenes de fronteriza». La designación de Santa Fe como puerto preciso en 1740 había atraído hacia Santa Fe, según Larramendi, a comerciantes de Tucumán, Cuyo, Córdoba, Paraguay, Perú y Chile. Ello había estimulado la demanda y había puesto en funcionamiento todas las actividades necesarias para abastecerla: explotación de huertas, chacras, quintas, sementeras y oficios conexos. Con su abolición, dieciocho quintas y chacras fueron abandonadas. Igual situación se dio con el servicio de almacenaje y transporte de efectos llegados de Paraguay y Misiones. El traslado ponía en funcionamiento el circuito de fletes que demandaba carretas o recuas, bueyes y maderas para la confección de los elementos de transporte. Todo ello generaba demanda adicional de servicios que repercutían en las inversiones en enseres y construcción de edificios. El mercado local se había beneficiado, además, con la llegada de todo género de efectos como cobre y añil de Chile, telas de lana y cordobanes de Córdoba, baquetas de Tucumán, cera y grano de Santiago del Estero; mulas y ganado de Buenos Aires; lana, atuendos, oro y plata del Perú. Ese suministro se había discontinuado, según el informe, paulatinamente a partir de la abolición del puerto preciso ${ }^{74}$.

Larramendi también apelaba a las trabas en la circulación comercial, uno de los objetivos prioritarios que el Consulado debía por cierto atender. La ubicación de Santa Fe frente al Chaco y Santiago del Estero, ciudad de paso

72 De hecho, Belgrano pensaba desde 1790 en la posibilidad de que su padre participara en sus planes de reactivación de la agricultura y comercio que luego fomentaría desde el Consulado, Halperin Donghi, 2014: 79-81.

73 “Informe del procurador Larramendi”, apéndice XXVII, Cervera, 1907: 129.

${ }^{74}$ Ibidem: 130. 
hacia Tucumán y Perú, la hacía cercana a ochenta leguas de desierto expuesto al ataque indígena. Desde allí, al entrar a Córdoba también debía atravesarse un desierto de cincuenta leguas para pasar a Cuyo y Chile. Estas dificultades, desde la falta de productos de Paraguay, hicieron desaparecer el aliciente para vencer el camino para los comerciantes ajenos a Santa $\mathrm{Fe}^{75}$.

La desigualdad en los gravámenes de fronteriza radicaba en el constante peligro de la jurisdicción frente a las poblaciones indígenas que hacía necesario por parte de los vecinos el abandono del cuidado de sus haciendas para atender en conjunto con otros la seguridad de una frontera vulnerada con frecuencia y que resultaba en la destrucción de haciendas, sementeras, edificios y asesinato de familias. Los vecinos debían marchar hacia la frontera con el fin de protegerla y prever una actividad constante de reuniones para decidir la mejor forma de organización interna para los relevos, abastecimientos y necesidades de defensa. Ello redundaba en que las explotaciones recibían una atención intermitente de sus titulares, hecho que se evidenciaba en una cuantía de oferta, variedad de producción y calidades menores de las probables en caso de una dedicación plena. El comercio, la actividad artesanal y todos los oficios posibles conexos sufrían el mismo menoscabo en su desarrollo ${ }^{76}$.

Un factor adicional de freno para el progreso, era lo mencionado como «poco gusto de las gentes del país». La idea consistía en que la población de la mayoría de los pueblos de América, compuesta en gran proporción por indios, mulatos y mestizos carecía de segmentos amplios de «vecinos de gusto», afectos a los artículos de calidad, de lujo y a la costumbre de incorporar en su dieta ingredientes propios de una buena y refinada degustación. Quienes sí lo hacían, desarrollaban sus propias huertas y medios para producirlos, con lo cual no había incentivos para promover un abastecimiento masivo, más allá de maíz, calabazas y batatas, base de la dieta general de las «gentes del país». Tampoco era factible pensar en la promoción de una industria ante «la ninguna propensión que tiene esta calidad de gentes al lujo, y aún, a una mediana decencia en los muebles, ropas y demás utensillos» y ante ello «no pueden tener otro estado la agricultura, industria y comercio sino el más miserable y mucho más habiendo imposibilitado casi enteramente su subsistencia ${ }^{77}$. En esto Larramendi coincidía desde un enclave en la periferia de la Monarquía con las teorías acerca del lujo debatidas en la Península. José Luis Villacañas Berlanga analizó como Juan Sempere y Guarinos, por ejemplo, veía en el lujo una fuente para el progreso y en su aceptación el ingreso

\footnotetext{
75 Ibidem: 131.

76 Ibidem: 132.

77 Ibidem: 132.
} 
de la Monarquía a una nueva etapa de su historia para su engrandecimiento, acorde al desarrollo europeo general. El mayor estímulo en las artes, industrias y comercio consistía en la multiplicación de los consumos. El lujo no era malo y nada civilizaba más a los hombres que el aumento de los intereses, relaciones entre sí y las necesidades ficticias. En esto, expresa Villacañas, Sempere y Guarinos evoca a Adam Smith e incluso a Immanuel Kant con la idea de permitir a los actores perseguir sus intereses, favoreciendo la libertad natural que se despliega en la mimesis, en el «contagio» ${ }^{78}$.

Para completar las circunstancias santafesinas desfavorables frente a Buenos Aires, la desigualdad de derechos era un freno adicional que evitaba que las embarcaciones con cargamento desde el Paraguay optaran por Santa $\mathrm{Fe}$ como puerto intermedio. Según Larramendi, todo comprador de efectos del Paraguay abonaba en la ciudad diecinueve reales tres cuartillos por cada tercio de yerba mate como derecho de salida, mientras que optar por Buenos Aires significaba pagar trece reales tres cuartillos. Al ser la plaza bonaerense la mayormente escogida en la comercialización, Santa Fe se veía privada de ingresos e imposibilitada hasta para fomentar los ramos «esenciales de su subsistencia».

En reunión de Cabildo del 9 de julio de 1795 se decidió entregar al diputado Candioti el informe para su elevación al Consulado con miras «al aumento y reanimación de la república». El escrito y el tratamiento en la misma reunión del modo de resolución de conflictos de límites entre Santa Fe y Corrientes demuestran que la administración de recursos era tema prioritario entre las ciudades del Virreinato. Por otro parte, el hecho de que Candioti y Larramendi fueran designados como diputados para felicitar al nuevo virrey en Buenos Aires - y cumplimentar en el mismo viaje debían la entrega prevista ante el Consulado y gestionar ante la Real Audiencia una resolución por el conflicto de delimitación jurisdiccional con Corrientes - demuestra que la lealtad santafesina a la autoridad virreinal se hallaba intacta ${ }^{79}$.

\section{Decisiones del consulado resPecto de Santa Fe: normativa y Realidad}

El Informe Larramendi proponía a las autoridades las medidas concretas que revertirían el malestar «sin el peligro de acarrear desavenencias políticas que perjudicaran aún más la situación» ${ }^{80}$. Las «desavenencias», —con Buenos

\footnotetext{
78 Villacañas Berlanga, 2013: 53.

79 AGPSF, ACSF, 09/07/1795, tomo XVI B, f. 308 v a 309 v.

80 "Informe del procurador Larramendi", apéndice XXVII, Cervera, 1907: 133.
} 
Aires - no serían novedad. El documento puede considerarse un ejemplo más, y esta vez ante el flamante Consulado, dentro de una serie de representaciones frente a las autoridades para defender posiciones que involucraron a Santa $\mathrm{Fe}$ y Buenos Aires a lo largo del siglo XVIII. Es además notorio que desde la diputación no se efectuó ninguna otra presentación o pedido ante el Consulado. Tampoco el diputado Candioti fungió como juez para dirimir conflictos ni se cumplió alguna otra instancia de las previstas por la cédula de erección de 1794 para promover el adelanto de la ciudad como uno de los espacios bajo jurisdicción del Consulado. La diputación habría tenido escasa significación, entonces, para Santa Fe.

Desde que los borbones habían considerado el comercio con América como uno de los principales motores de rehabilitación económica, la elite comerciante bonaerense sumó esfuerzos para aprovechar la expansión renovada del Río de la Plata. Buenos Aires amplió su capacidad para captar los flujos comerciales de su hinterland que serían clave de su incorporación futura en el mercado global. Comerciar en Buenos Aires era una actividad rentable, tanto como en Potosí y no se hacía necesario el traslado hasta Santa $\mathrm{Fe}$ para una salida hacia el mar u obtener metálico o mercancías $^{81}$. Sin embargo, también se analizó cómo Santa Fe fue convirtiéndose desde el siglo XVII en un importante centro de redistribución con crecimiento propio frente a Buenos Aires.

Las asperezas entre los vecinos del circuito económico de ambas ciudades pueden seguirse en documentos anteriores al Informe Larramendi. En ese sentido, cuando en 1719 el gobernador Bruno de Zavala fijó una serie de impuestos, aprobados por la Real Audiencia, para aportar a la defensa de Santa Fe frente a su problema recurrente de ataques de las poblaciones indias circundantes, las quejas vía presentaciones de comerciantes de Buenos Aires y Asunción fueron inmediatas. Finalmente, el virrey del Perú rechazó la medida por el daño que semejante beneficio para Santa Fe produciría en el comercio bonaerense y asunceño ${ }^{82}$. En 1724 los capitulares santafesinos enviaron, evitando recurrir a Buenos Aires, una representación directamente a España de la mano de Antonio Fuentes del Arco y Godoy con la solicitud de apoyo militar y económico para la ciudad ${ }^{83}$. Luego de negociaciones, una Real Cédula restableció los impuestos vetados en 1719 y comenzó el debate para

${ }^{81}$ Garavaglia, 1987: 67.

82 Archivo General de Indias, Sevilla, en adelante AGI, Charcas, 23, 310, Expediente sobre los arbitrios concedidos a la ciudad de Santa Fe de la Vera Cruz. Años 1719-1746, citado en Tarragó, 2012: 281.

83 Cervera, 1907: 455. 
implementar los mecanismos de pago de impuestos por los que Santa Fe sería «puerto preciso» para todos las embarcaciones provenientes de Asunción ${ }^{84}$. La resistencia a la medida fue inmediata porque usar el puerto de Las Conchas en el norte de Buenos Aires, más cercano al Atlántico y más accesible que Santa $\mathrm{Fe}$ era la opción preferida que muchos comerciantes no pretendían abandonar ${ }^{85}$. Dos años más tarde, en 1732, el gobernador de Buenos Aires sometió el tema a consideración ante el Consejo de Indias y ante la falta de solución satisfactoria los bonaerenses apelaron en 1737 a la Audiencia de Charcas. No obstante, la corona ratificó el privilegio con la Real Cédula de 1743 que mantuvo vigencia hasta $1780^{86}$.

Los importantes beneficios en juego para la elite santafesina por el puerto preciso y el mencionado juego de los actores locales se observan en la figura de José de Lacoizqueta, quien financió la totalidad del proceso asegurándose posterior recompensa con la obtención del cargo de recaudador de impues$\operatorname{tos}^{87}$. Los comerciantes bonaerenses no dejaron de presentar en esa oportunidad sus quejas por creer que unos pocos santafesinos, «los confederados» (remitiendo a una asociación formal) eran los únicos beneficiados. Siendo propietarios de tierras, ganado y estancias, éstos subordinaban al resto de la población santafesina mediante el control de los suministros de la ciudad y su entorno para vender sus producciones a precios irrazonables, sacando ventajas de la necesidad local ${ }^{88}$. Buenos Aires, Santa Fe y Asunción continuaron presentando sus pareceres en los años siguientes respecto del puerto preciso ante la Audiencia de Charcas y el Consejo de Indias. Contra Santa Fe se reclamó en octubre de 1769 y los comerciantes de esta ciudad se defendieron, por su parte, en febrero de 1776 con una representación ante el rey y el 22 de febrero de 1778 ante el virrey Ceballos con el pedido de reconocimiento de sus derechos ${ }^{89}$. Entre los diversos testimonios contra Santa Fe es elocuente el de Juan de la Rosa, comerciante residente en Asunción quien declaró que en la «tierra de Lacoizqueta» y otros prominentes santafesinos el comercio ilícito de licor, negros y mulas con barcos portugueses era visto por todo el distrito, en especial las islas que servían de lugar de descarga ${ }^{90}$.

\footnotetext{
${ }^{84}$ AGI, Charcas, 310, f. 70 r-v.

85 AGI, Charcas, 310, 1730, f. 90.

86 AGI, Charcas, 325, Expediente sobre que la ciudad de Santa Fe de la Vera Cruz sea puerto para los que bajan del Paraguay. Años 1726-1758, citado en Tarragó, 2012: 282.

87 AGI, Charcas, 310, leg. 9, 1719-1726.

88 AGI, Charcas, 325, leg. 26, julio 1752.

89 Damianovich, 1986: 9-44. Tarragó, 2012: 283.

90 Testimonio presentado por representantes de Buenos Aires y Asunción, AGI, Charcas, 325, leg. 19 a, f. 29.
} 
Además de las presentaciones anteriores, las actas del cabildo santafesino documentan quejas y reclamos. En 1744, por ejemplo, se reclamó al gobernador el cese de desembarcos en el puerto de Las Conchas en Buenos Aires en lugar del santafesino declarado como puerto preciso. Se intimaba que el gobernador lograse restablecer el comercio que Buenos Aires le había usurpado a la ciudad ${ }^{91}$. Ante la continuidad de la situación, en 1750 el Cabildo insistió en que la libertad para que las embarcaciones prosiguieran a Buenos Aires era inaceptable y significaba desconocer los derechos de Santa Fe para adjudicárselos a Buenos Aires ${ }^{92}$. Además de los reclamos, Santa Fe tomó medidas concretas de control como la designación de ministros de jurisdicción encargados de verificar las descargas y cargas de barcos arribados del Paraguay $^{93}$. De 1750 hasta la década de 1770 inclusive se sucedieron los reclamos y presentaciones. Desde dueños de embarcaciones que declaraban el mejor trato que recibían en Buenos Aires hasta denuncias por irregularidades y mercancías no permitidas escondidas que justificaban revisar cada uno de los barcos llegados a Santa Fe son algunos de temas que muestran la tensión y conflictos de competencia entre Santa Fe y Buenos Aires ${ }^{94}$.

Así el Informe Larramendi es el único testimonio del mismo tenor, pero desde una diputación del Consulado de Buenos Aires. Las propuestas de 1795 del procurador como representante del comercio y hacendados santafesinos eran precisas y la descripción previa de un exagerado panorama desolador no hacía más que incitar a decisiones inmediatas: el restablecimiento del puerto preciso; el logro de una buena comunicación y tránsito con la provincia de Tucumán y la igualdad en los derechos de salida para los efectos del Paraguay. El puerto preciso proveía el beneficio adicional de ahorrar a los conductores cien leguas de camino hacia Santiago del Estero, ochenta hacia Córdoba y casi setenta hasta Mendoza; lo que significaba una disminución en la mitad de los costos de fletes, peones, demoras y peligros en la travesía. Si se agregaba la igualdad de derechos frente a Buenos Aires, solo restaba el tema de la seguridad. Para ello, preveía la erección de una nueva fortaleza en el paraje de los «Altos o Monigote» o trasladar una ya existente en «el Tío», en la jurisdicción de Córdoba, hacia ese lugar. Esa simple previsión, solventada con la mitad de los derechos que abonaban las carretas al gobierno de Córdoba

91 AGPSF, ACSF, 13/04/1744, tomo XI, f. 222-224.

92 AGPSF, ACSF, 26/08/1750, tomo XII, f. $112 \mathrm{v}-113 \mathrm{v}$.

93 AGPSF, ACSF, 17/03/1742, tomo XI, f. 83 v-86.

94 Véanse AGPSF, ACSF, 29/04/1754, tomo XII, f. 238-239v; 28/05/1770, tomo XVI, f. 73-75; 05/08/1776, tomo XVI, f. 419-420, y otros casos de ese lapso temporal considerados en Cecchini, 2016: 83-108. 
daba, según el informe, no solo garantías de seguridad, sino pasturas, aguadas y pascanas cómodas para tropas y viajeros, sobre todo si se agregaba al fuerte la posibilidad de ofrecer postas y correspondencia mensual como en las demás ciudades de las provincias ${ }^{95}$. El traslado del fuerte significaba llevar la fortificación desde El Tío, en el actual departamento de San Justo en el centroeste de Córdoba, a unos 216 kilómetros hacia el noreste en jurisdicción santafesina hasta Monigotes, actual departamento San Cristóbal a 187 kilómetros al noroeste de la ciudad de Santa Fe.

Sin embargo, el informe no fue considerado. Durante el periodo de diputación de Francisco Candioti, Santa Fe no fue tenida en cuenta en las reuniones del Consulado y tampoco se observan peticiones adicionales de Candioti para lograr la inclusión de la jurisdicción entre los temas de debate. Los problemas tratados durante las sesiones del Consulado se dirimieron en función de otras ciudades y necesidades. La Junta de gobierno de la institución debía, según la Real Cédula de Erección de 1794, poner especial énfasis en lograr la construcción de caminos y el establecimiento de rancherías en los despoblados para mejor comunicación y comodidad en los transportes. Debía, además, asegurar la limpieza permanente del puerto de Montevideo — de particular importancia para la región - y lograr la construcción de un muelle o desembarcadero adecuado en Buenos Aires para cargas y descargas sin riesgos de averías ${ }^{96}$.

Si bien excede el objetivo de este trabajo un análisis exhaustivo de las cuestiones tratadas por el Consulado, pueden citarse como ejemplos la consideración del trazado de caminos en la ruta al Alto Perú, exploraciones en la comunicación hacia Chile, el camino entre Córdoba y Catamarca, o caminos de acceso a Buenos Aires. Otro tema fue el análisis de la necesidad de ampliar las diputaciones a ciudades claves del tráfico comercial, como Catamarca, desestimada en el análisis preliminar de factibilidades ${ }^{97}$. También interesaba la recaudación de donativos para gestionarlos, completarlos y entregarlos al secretario de Estado y del Despacho Universal de Hacienda de España e Indias como representante de la corona ${ }^{98}$. El puerto de Monte-

95 “Informe del procurador Larramendi”, apéndice XXVII, Cervera, 1907: 133.

${ }^{96}$ Real cédula de erección del Consulado de Buenos Aires, 30 de enero de 1794, Consulado de Buenos Aires, Antecedentes-Actas-Documentos, I, 1785-1795, AGNA, Kraft ltda., Buenos Aires, 1936, Apéndice, láminas VII, XVIII.

${ }^{97}$ Comunicación al Consulado, 25/11/1794, Consulado de Buenos Aires, AntecedentesActas-Documentos, I, 1785-1795, AGNA, Kraft ltda., Buenos Aires, 1936, 263.

98 A modo de ejemplo, el virrey Nicolás de Arredondo, hizo saber en diciembre de ese primer año de erección su recepción conforme del oficio del Consulado en que se le imponía de haberse completado los 100.000 pesos fuertes ofrecidos a su majestad como donativo para 
video, como se dijo, fue uno de los enclaves de mayor alusión, al igual que consideraciones sobre el tráfico de esclavos negros; controles sobre la recaudación y las entregas del derecho de avería, sostén financiero del Consulado $^{99}$. Otro aspecto de intervención eran los habituales inconvenientes en el tráfico comercial terrestre en la jurisdicción del Consulado ${ }^{100}$. Las recaudaciones mensuales en las aduanas era otro de los temas que generaba comunicaciones y rendiciones ${ }^{101}$. De igual modo, el procedimiento a seguir en caso de ausencia de diputados era motivo de frecuentes consultas, lo cual evidencia quizá la poca atención o interés de las diputaciones por participar en la gestión promovida desde el Consulado ${ }^{102}$.

Aunque la realización de obras, además de la promoción de centros de educación con ideas innovadoras propias del periodo borbónico, estaba entre las finalidades previstas para el Consulado por la legislación de la Monarquía, algunas investigaciones concluyeron que en la práctica sus miembros no cedieron sus intenciones mercantilistas y continuaron las estrategias conocidas y generadoras de resultados desde el periodo de las Juntas. El comercio de exportación fue una de las preocupaciones principales, basado en el tráfico de cueros tópico que fundamenta el conflicto con los hacendados a inicios de 1790. Proyectos novedosos, como los de Manuel Belgrano, habrían sido frenados en su impulso innovador por pares que no estaban tan convencidos de aplicar ideas modernizadoras ${ }^{103}$. Si bien Belgrano pretendía incorporar en el Río de la Plata las teorías europeas que había incorporado en su formación extranjera, la capacidad modernizadora en la institución no fue uniforme y objetivos diversos impulsaban al cuerpo, oponiéndose a Belgrano y dando

hacer frente a la guerra sostenida en Europa durante ese año. Comunicación al Consulado, 01/12/1794, Consulado de Buenos Aires, Antecedentes-Actas-Documentos, I, 1785-1795, AGNA, Kraft ltda., Buenos Aires, 1936, 264.

${ }_{99}$ Acta del 5/12/1794, Acta 12/12/1794, Informe del administrador de la Aduana de Montevideo diciembre 1794, Consulado de Buenos Aires, Antecedentes-Actas-Documentos, I, 1785-1795, AGNA, Kraft 1tda., Buenos Aires, 1936, 266; 272; 289.

${ }^{100}$ En enero de 1795 se comisionó a Juan Antonio de Caldera y Verbal para averiguar la desaparición de una carga de doblones perdida en la Cordillera de los Andes. Desde la ciudad de Mendoza, el enviado informó al Consulado su decisión de organizar una estadía en Santiago de Chile para efectuar las diligencias necesarias a la investigación. Comunicaciones San Juan-Mendoza, Consulado de Buenos Aires, Antecedentes-Actas-Documentos, I, 1785-1795, AGNA, Kraft ltda., Buenos Aires, 1936, 303.

101 Correspondencia con Montevideo, Consulado de Buenos Aires, Antecedentes-ActasDocumentos, I, 1785-1795, AGNA, Kraft ltda., Buenos Aires, 1936, 312.

102 Acta del 13/04/1795, Consulado de Buenos Aires, Antecedentes-Actas-Documentos, I, 1785-1795, AGNA, Kraft ltda., Buenos Aires, 1936, 332.

103 Kraselsky, 2011: 58-59. 
lugar a enfrentamientos. Ellos se reflejaban en las actas de deliberaciones, con la defensa de la agricultura en contradicción a los principios liberales del comercio, los beneficiados por el comercio ilegal o los partidarios del monopolio comercial entre otros puntos que revelan el carácter heterogéneo del grupo consular, oscilante entre la tradición y la modernización liberal ${ }^{104}$.

Mención aparte merecen las consideraciones acerca del comercio en y desde Potosí, en especial, el establecimiento del régimen de situadistas y nombramiento de conductores de caudales de particulares a Buenos Aires, cuestión que involucró en particular a los diputados de Potosí y Salta ${ }^{105}$. La ciudad de Santa Fe no es mencionada en el proceso de consideración del sistema. Tampoco estuvo entre las consideradas para el renovado sistema de transporte de caudales. De hecho, no se la cita al momento de definir las exacciones por flete a favor de los comerciantes transportistas, cargos previstos en función de los lugares de salida (Potosí y Chuquisaca) y destino; siendo estos últimos la provincia de Chichas, Jujuy, Salta, San Miguel de Tucumán, Santiago del Estero, Córdoba y Buenos Aires. Tampoco se la preveía como lugar de parada por término de un día, obligación que debía cumplir el situadista para recibir caudales provenientes del comercio a remitir, en Chichas, Santiago de Cotagaita, Jujuy, Salta, San Miguel de Tucumán, Santiago del Estero y Córdoba ${ }^{106}$. Esta falta de consideración respecto de Santa Fe hace notorio que la ciudad no estaba incluida en la agenda de lugares a priorizar, ello en concordancia con la política que había llevado a la supresión de su privilegio de puerto preciso en 1780; es evidente que no existían intenciones de atender a su prosperidad desde el Consulado, a pesar de la solicitud de un informe sobre su situación general.

La solicitud de información acerca del estado de la agricultura, industria y comercio que Candioti recibió para Santa Fe en abril de 1795, fue una de las varias que el Consulado emitió para otras jurisdicciones en cumplimiento de la normativa ${ }^{107}$. Para el caso de Santa Fe pareciera haberse tratado de una mera formalidad. La ciudad no parecía interesar a Buenos Aires.

104 Gelman, 2005: 467-488.

105 Acta del 04/03/1795, Consulado de Buenos Aires, Antecedentes-Actas-Documentos, I, 1785-1795, AGNA, Kraft ltda., Buenos Aires, 1936, 325.

106 Reglamento dispuesto en Junta de Gobierno del Real Consulado, 13/05/1795, Consulado de Buenos Aires, Antecedentes-Actas-Documentos, I, 1785-1795, AGNA, Kraft 1tda., Buenos Aires, 1936, 350.

107 Comunicaciones del Consulado a Tucumán, Santa Fe, y Corrientes; Comunicaciones del Consulado a Salta, Catamarca y Santiago del Estero, Consulado de Buenos Aires, Antecedentes-Actas-Documentos, I, 1785-1795, AGNA, Kraft ltda., Buenos Aires, 1936, 282 y 323. 
El mandato de Candioti ante el Consulado finalizó en julio de 1796 en que fue reemplazado por Juan Francisco Larrechea. Los diputados siguientes fueron Agustín de Iriondo (1798-1800), Manuel Ignacio Diez de Andino (1800-1802), Quirze Pujato (1802-1804), José Arias Troncoso (1804), Juan Francisco Larrechea (1804), José Pujol y Viladelmás (1804-1806), Adrián de Arriola (1806-1808) y Francisco de Alzogaray (1808-1810). Para 1810 se designó a Juan Francisco de Tarragona, quien fue nombrado vocal de la Junta Suprema Gubernativa. Para 1813 se designó a Manuel Francisco Maciel hasta $1816^{108}$. En todo ese período sólo Alzogaray logró cierta consideración $^{109}$. Consistió en la mejora del camino hacia el norte, por el Litoral, con una serie de obras beneficiosas para la ciudad santafesina propuestas por el diputado en $1809^{110}$.

No obstante, las decisiones del Consulado y la desatención de Santa Fe, el contenido del Informe Larramendi representaba en sí mismo un relato que buscaba movilizar instancias de decisión en favor de los intereses regionales de los santafesinos. Durante todo el siglo se había operado en igual sentido, con diferentes instancias de representación ante las autoridades. El documento exponía argumentaciones que no reflejaban la realidad económica. Por medio de un panorama en exceso desolador se buscaba torcer las decisiones del poder político para incrementar los beneficios de una región que por sí sola mostraba un desarrollo propio gracias al accionar exitoso de sus agentes individuales vinculados a nivel local y suprarregional; aun cuando pudiese tratarse de un grupo minoritario como se dijera a propósito del grupo representado por Lacoizqueta.

108 Tjarks, 1962: 946.

109 AGPSF, ACSF, 31/10/1805, 11/02/1806, tomo XVII A, f. 242v-244v y f. 266v-269v. AGPSF, ACSF, 07/10/1810, Acuerdos de 1810, f. 30-34.

${ }^{110}$ Incluyó el despeje de una franja de dos leguas de selva impenetrable bordeando el Colastiné que dificultaba el acercamiento a la ribera sur de la costa del Paraná y encarecía fletes. Alzogaray presentó plano detallado de la zona del Colastiné y presupuesto de costos de trabajo por 300 pesos aprobado por el Consulado el 27 de noviembre de 1809. También incluyó una propuesta de puente sobre el Salado que daba a Santa Fe un acceso directo a la ruta de Córdoba desde el oeste, pero la solicitud fue postergada. Ésta última volvió a ser desestimada en 1812 cuando fue requerida por el diputado José Alberto Calcena. Tjarks, 1962: 701-760. 
Mapa 1. Espacio santafesino con el curso fluvial del Paraná de norte a sur hasta el Paraguay a 1200 Km de distancia y la Salida Por el Río De la Plata a 550 KM

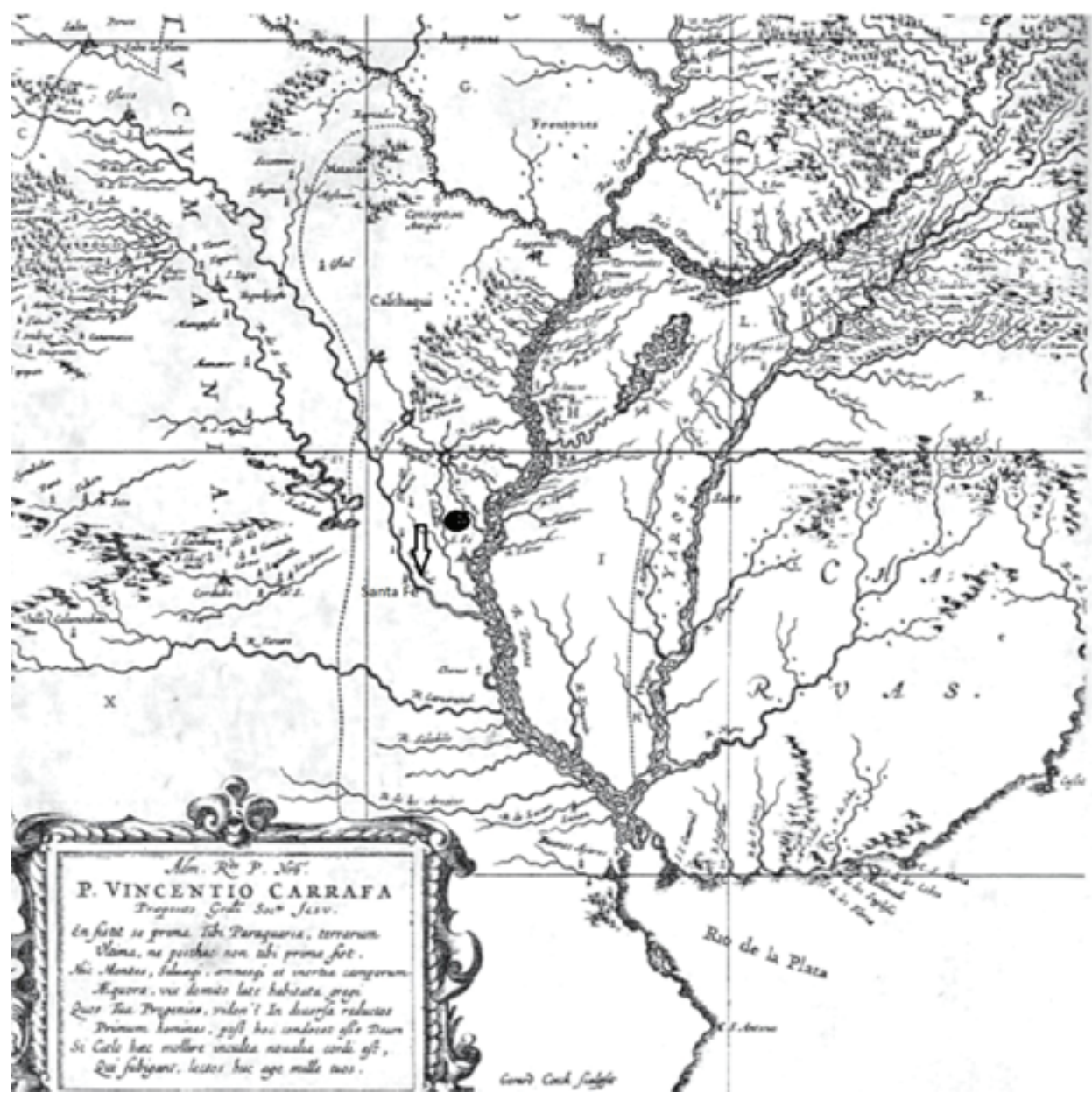

Fuente: Cervera y Cervera, 2016: 45. 
Mapa 2. Puerto de Las Conchas en Buenos Aires en competencia con el SANTAFesino frente a Colonia del Sacramento

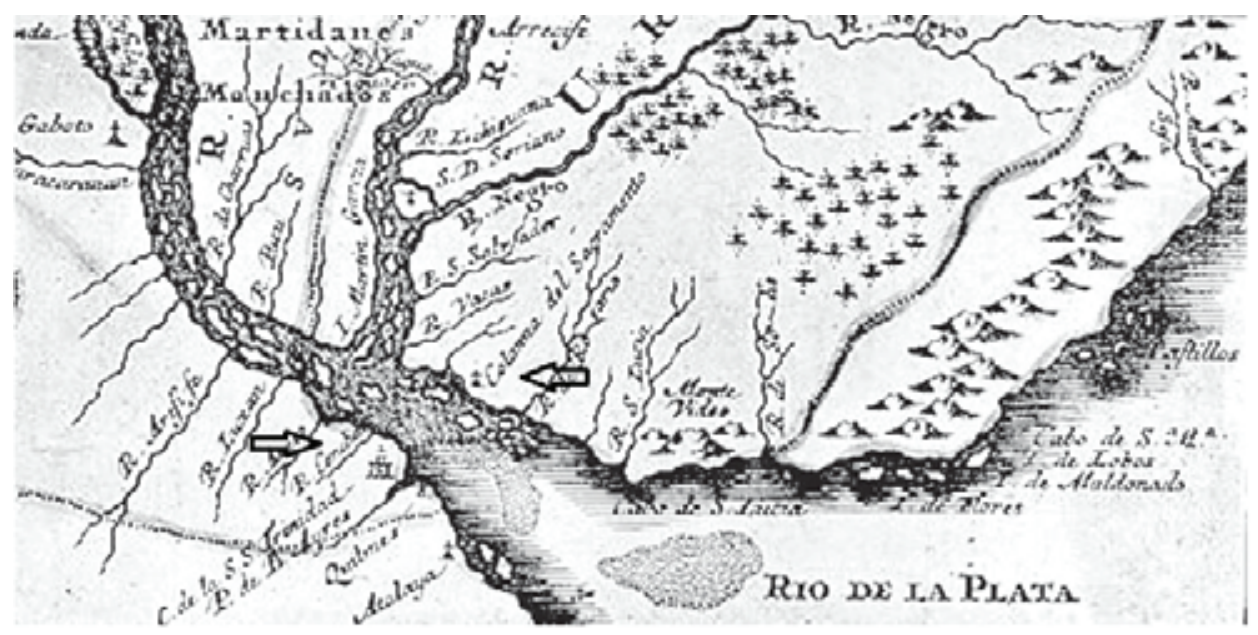

Fuente: Cecchini, 2016: 82.

\section{Conclusiones}

Los consulados de comercio, creados en América como herramienta de una política borbónica que buscaba reordenar sus posesiones de ultramar para superar una situación que se percibía de decadencia a nivel general, constituyen, a partir de las relaciones con sus diputaciones, un observatorio que permite evidenciar problemas locales subyacentes más allá de la normativa y los objetivos de la Corona.

El Informe Larramendi de 1795 es un ejemplo concreto de las tensiones que en el Río de la Plata existían entre la capital del Virreinato, Buenos Aires, y la ciudad de Santa Fe, bisagra comercial ubicada a menos de 300 kilómetros al norte de aquella. Por su importancia, Santa Fe contó con una diputación dependiente del consulado de comercio bonaerense, creada a partir de la directiva Real de establecerlas en los lugares más convenientes para la promoción del progreso de toda la jurisdicción del Consulado.

El documento elaborado y presentado por dos miembros de la elite comerciante santafesina expresaba la disconformidad de toda la población por el trato inequitativo recibido de parte de Buenos Aires desde muchos años antes de la erección del Consulado. A pesar de la inacción bonaerense para mejorar la situación desfavorable que atravesaba desde hacía mucho Santa Fe, los 
santafesinos extremaban esfuerzos para superar por su cuenta los inconvenientes y encauzar el desarrollo de sus actividades hacia el atlántico en respuesta a la tendencia general que venía desarrollándose en el sur de América. Tanto Larramendi, el autor del informe, como el diputado Candioti son ejemplos de quienes con éxito habían continuado actividades a pesar de la supresión del privilegio del puerto preciso de $1780 \mathrm{y}$ otras desventajas denunciadas en el escrito. Estos hombres representaban a una elite santafesina de asentamiento tardío en el Virreinato, aquellos que habían escalado posición social y económica, además de detentar los principales cargos del cabildo local desde la segunda mitad del siglo XVIII.

La letra del escrito demuestra, además, que los santafesinos estaban al corriente de las ideas imperantes en la Península acerca de los beneficios del consumo y del lujo, así como el fomento de la agricultura y en especial los textiles; proyecto compartido por Manuel Belgrano, secretario del consulado bonaerense, miembro de la elite comerciante porteña e impulsor de las nociones Ilustradas en boga sobre educación, comercio, agricultura y manufacturas que adquiera en su formación en Salamanca y Valladolid. En esto el trabajo es un aporte para repensar el concepto de Ilustración y las reformas borbónicas en los contextos periféricos de la monarquía hispánica y más allá de Buenos Aires, principal referente cuando se habla del Río de la Plata.

La respuesta del consulado de Buenos Aires a los requerimientos santafesinos contenidos en el informe, que ofrecía además soluciones puntuales, fue de total indiferencia. Pareciera que la solicitud a Santa Fe de un relevamiento detallado sobre el estado de la jurisdicción, se hubiese tratado tan solo del cumplimiento formal de las obligaciones que la Real Cédula de Erección preveía en ese sentido para el Consulado. Ni la institución consideró a Santa $\mathrm{Fe}$ en sus deliberaciones, ni tampoco Santa Fe volvió a efectuar peticiones por medio de la diputación. Más aún, el mismo diputado Candioti desconfió desde el inicio de las posibles ventajas a conseguir frente a Buenos Aires con la diputación ya que intentos anteriores por otras vías habían resultado infructuosos.

En síntesis, el caso de la diputación santafesina frente al consulado bonaerense ofrece una puerta de acceso al análisis de la relación entre intenciones de la Corona, Ilustración y conflictos internos latentes en los espacios gobernados por la política borbónica en la segunda mitad del siglo XVIII. Enclaves donde si bien las elites locales, como la santafesina, no ponían en duda su lealtad a la Corona ya se evidenciaban rivalidades con la capital virreinal que se agudizarían en la primera década del siglo siguiente. Ello tornaría sumamente difícil la gobernabilidad desde la capital luego del estallido revolucionario de 1810, momento en que los santafesinos mencionados en este trabajo 
tuvieron un rol protagónico en el gobierno de su ciudad y con relación a Buenos Aires.

\section{BIBLIOGRAFÍA}

Assadourian, Carlos Sempat, El sistema de la economía colonial. El mercado interior. Regiones y espacio económico, México, Nueva Imagen, 1983.

Astigarraga, Jesús, "Las Reflexiones (1761) de Simón de Aragorri y la reforma del comercio atlántico español", Revista de Indias, LXXIII/259 (Madrid, 2013): 759-788.

Belgrano, Manuel, "Memoria escrita por el licenciado Manuel Belgrano, abogado de los reales consejos y secretario por su majestad del real consulado de Buenos Aires en 1797", Documentos del Archivo de Belgrano, Buenos Aires, Museo Mitre, Imprenta Coni, 1913, tomo 1: 80-92.

Bistué, Noemí y Acevedo, Alba, "De traficantes y negociantes y sus conflictos. La administración de justicia mercantil en la Mendoza virreinal (1776-1810), Revista Cruz de Sur, 14 (Buenos Aires, 2015): 357-391.

Brading, David, Mineros y comerciantes en el México borbónico (1763-1810), México, Fondo de Cultura Económica, 1983.

Brunner, Otto, "La casa grande y la oeconomica de la vieja Europa", Nuevos caminos de la historia social y constitucional, Buenos Aires, Alfa, 1976: 87-123.

Candioti, Agustín, Francisco Antonio Candioti y Zeballos. Primer gobernador independiente de Santa Fe. Su actuación durante el Virreinato del Río de la Plata y la Independencia Nacional, Buenos Aires, Academia Nacional de Agronomía, 1960.

Cansanello, Oreste Carlos, "Ciudadano / Vecino", Noemí Goldman (ed.), Lenguaje y revolución. Conceptos políticos clave en el Río de la Plata, 1780-1850, Buenos Aires, Prometeo, 2008: 19-34.

Caula, Elsa, "Las configuraciones mercantiles a escala de imperio a finales del período colonial: Pautas de comportamiento, circulación de recursos y experiencia", Anuario del Instituto de Historia Argentina, 11 (La Plata, 2011): 153-181.

Cecchini, Ana María, "Santa Fe, Asunción, Buenos Aires. Un espacio comercial conflictivo. Siglos XVII, XVIII y XIX. La mirada de los santafesinos", Revista América, 25 (Santa Fe, 2016): 67-110.

Cervera, Felipe, "Nepotismo y economía en Santa Fe, siglos XVII a XX", Junta Provincial de Estudios Históricos, LXIV (Santa Fe, 2004): 5-33.

Cervera, Felipe y Cervera, Mónica, "Santa Fe La Vieja: la creación de sociabilidad, Revista América, 25 (Santa Fe, 2016): 39-65. 
Cervera, Manuel, Historia de la ciudad de Santa Fe, 1573-1853, Santa Fe, Imprenta La Unión, 1907, tomo 1.

Cervera, Manuel, "Don Francisco Antonio Candioti - Primer Gobernador Independiente de Santa Fe, 1743-1815", Revista de la Junta Provincial de Estudios Históricos, 7 (Santa Fe, 1942).

Clavero, Bartolomé, Antidora. Antropologia católica de la economía moderna, Milán, Giuffrè Editore, 1991.

Cornejo, Florencia, "El litoral, Salta y el Perú unidos por una compañía de mulas (Olavegoya-Candioti), 1798-1810”, Boletín del Instituto San Felipe y Santiago, IX/31 (Salta, 1979): 101-113.

Cruz Barney, Oscar, "Operaciones mercantiles y consulados de comercio en el mundo Hispano-Indiano: notas sobre su estudio", América Latina en la Historia Económica, 9/17-18 (México, 2002): 157-168.

Cruz Barney, Oscar, "Las diputaciones foráneas del consulado de México: 1807 y 1816", Antonio Ibarra y Guillermina del Valle Pavón (coords.), Redes sociales e instituciones comerciales en el imperio español, siglos XVIII a XIX, México, Instituto Mora, 2007: 295-325.

Damianovich, Alejandro, "En torno a la antigüedad de privilegio santafesino de Puerto Preciso", Revista de la Junta Provincial de Estudios Históricos de Santa Fe, 56 (Santa Fe, 1986): 9-44.

Damianovich, Alejandro, "Juan José de Lacoizqueta, gestor del privilegio santafesino de Puerto Preciso", Revista América, 10 (Santa Fe, 1991): 37-70.

Damianovich, Alejandro, "Santa Fe y la redistribución regional del poder en la temprana revolución rioplatense", Revista de la Junta Provincial de Estudios Históricos de Santa Fe, 63 (Santa Fe, 2010): 73.

De Azara, Félix, Viajes inéditos. Desde Santa Fe a la Asunción, al interior del Paraguay, y a los pueblos de Misiones, Buenos Aires, Imprenta y Librería de Mayo, 1873.

Del Valle Pavón, Guillermina, “Contraprestaciones por los servicios financieros del Consulado de México y sus miembros: los fondos extraordinarios para la guerra contra Gran Bretaña, 1779-1783”, Revista complutense de historia de América, 41 (Madrid, 2015): 149-171.

Fernández Sebastián, Javier, "Península Ibérica”, Vincenzo Ferrone y Daniel Roche (eds.), Diccionario histórico de la Ilustración, Madrid, Alianza Editorial, 1998: 340-351.

Finestrad, Joaquín de, El vasallo instruido en el estado del nuevo reino de Granada y en sus respectivas obligaciones, Bogotá, Universidad Nacional de Colombia, 2000 . 
Garavaglia, Juan Carlos, Economía, sociedad y regiones, Buenos Aires, Ediciones de La Flor, 1987.

Garavaglia, Juan Carlos, Mercado interno y economía colonial. Tres siglos de historia de la yerba mate, Rosario, Prohistoria Ediciones, 2008.

Gelman, Jorge, De mercachifle a gran comerciante. Los caminos del ascenso en el Río de la Plata colonial, La Rábida, Universidad Internacional de Andalucía, 1996.

Gelman, Jorge, "Derechos de propiedad, crecimiento económico y desigualdad en la región pampeana, siglos XVIII y XIX", Historia agraria: Revista de agricultura e historia rural, 37 (Murcia, 2005): 467-488.

Grieco, Viviana, The politics of giving in the Viceroyalty of Rio de la Plata: donors, lenders, subjects and citizens, Albuquerque, University of New México Press, 2014.

Guerrero Elecalde, Rafael, "Las elites vascas y navarras en el gobierno de la Monarquía borbónica: redes sociales, carreras y hegemonía en el siglo XVIII (17001746), Bilbao, Editorial de la Universidad del País Vasco, 2012.

Halperin Donghi, Tulio, "El Río de la Plata al comenzar el siglo XIX", Revolución y Guerra. Formación de una elite dirigente en la Argentina criolla, Buenos Aires, Siglo XXI, 1972.

Halperin Donghi, Tulio, Reforma y disolución de los imperios ibéricos, 1750-1850, Madrid, Alianza, 1985.

Halperin Donghi, Tulio, El enigma Belgrano. Un héroe para nuestro tiempo, Buenos Aires, Siglo XXI, 2014.

Hernández García, Elizabeth, "Las familias piuranas y su capacidad de comercialización en la segunda mitad del siglo XVIII", Mercurio Peruano, 526 (Lima, 2013): 123-141.

Ibarra, Antonio, "El Consulado de Comercio de Guadalajara: entre la modernidad institucional y la obediencia a la tradición, 1795-1818", Guillermina del Valle Pavón (coord.), Mercaderes, comercio y consulados de Nueva España en el siglo XVIII, México, Instituto Mora, 2003: 310-334.

Ibarra, Antonio, Mercado e institución: corporaciones comerciales, redes de negocios y crisis colonial. Guadalajara en el siglo XVIII, México, UNAM / Bonilla Artigas Editores, 2017.

Imízcoz Beunza, José María, "Las élites vasco-navarras y la Monarquía Hispánica: construcciones sociales, políticas y culturales en la Edad Moderna", Cuadernos de historia moderna, 33 (Madrid, 2008): 89-119. 
Jumar, Fernando, "Comerciantes en Río de la Plata pre-virreinal. El caso de Domingo de Basavilbaso", Anuario del Instituto de Historia Argentina, 11 (La Plata, 2011): 207-241.

Jumar, Fernando, "El comercio ultramarino por el complejo portuario rioplatense y la economía regional, 1714-1778", Magallánica: revista de historia moderna, 3/5 (Mar del Plata, 2016): 166-259.

Jumar, Fernando y Kraselsky, Javier, "Las esferas del poder. Hacendados y comerciantes de Buenos Aires ante los cambios de la segunda mitad del siglo XVIII", Anuario del Instituto de Historia Argentina, 7 (La Plata, 2007): 31-58.

Kraselsky, Javier, Las estrategias de los actores del Río de la Plata: Las Juntas y el Consulado de Comercio de Buenos Aires a fines del Antiguo Régimen, 1748-1809, Memoria Académica, tesis de doctorado Universidad Nacional de La Plata, Facultad de Humanidades y Ciencias de la Educación, 2011.

Kraselsky, Javier, "El Consulado de comercio de Buenos Aires y sus redes económicas y políticas: las Diputaciones de Potosí y Montevideo, 1795-1812", El Taller de la Historia, 8/8 (Cartagena, 2016): 3-35.

Kuethe, Allan y Andrien, Kenneth, The Spanish Atlantic World in the Eighteenth Century: War and the Bourbon Reforms, 1713-1796, Cambridge, Cambridge University Press, 2014.

Langue, Frédérique, "Las élites en América española: actitudes y mentalidades", Boletín Americanista, $42 / 43$ (Barcelona, 1992): 123-139.

Martínez Martín, Carmen, “Aportaciones cartográficas de Félix de Azara sobre el Virreinato del Río de la Plata", Revista complutense de historia de América, 23 (Madrid, 1997): 167-192.

Mazzeo, Cristina, Gremios mercantiles en las guerras de la independencia. Perú y México en la transición de la colonia a la República, 1740-1840, Lima, Instituto de Estudios Peruanos, 2012.

Milano, Adriana, Un liderazgo local entre el virreinato y la revolución. Santa Fe siglos XVIII-XIX: Francisco Antonio Candioti (1743-1815), tesis de doctorado Universidad Nacional de Rosario, Facultad de Humanidades y Artes, 2018.

Milano, Adriana, "Entre influencia ilustrada europea y necesidades de un espacio periférico: el Consulado de Comercio de Buenos Aires como ámbito de experimentación y difusión de la Economía Política a fines del siglo XVIII", Anuario Del Instituto De Historia Argentina, 19/1 (La Plata, 2019): 1-23.

Pagden, Anthony, Señores de todo el mundo. Ideologías del imperio en España, Inglaterra y Francia (en los siglos XVI, XVII y XVIII), Barcelona, Península, 1997.

Palti, Elías, Una arqueología de lo político. Regímenes de poder desde el siglo XVII, Buenos Aires, Fondo de Cultura Económica, 2018. 
Paredes, Isabel, "La carrera del Paraguay a fines del siglo XVIII", América Latina en la Historia Económica, 21/1 (México, 2014): 66-80.

Portillo Valdés, José María, "Ilustración, nación e imperio en la monarquía española", Araucaria, Revista Iberoamericana de filosofía, política, humanidades y relaciones internacionales, 40 (Sevilla, 2018): 59-73.

Quarleri, Lía, "Expediciones, narrativas y utopías: nuevas miradas sobre el espacio guaranímisionero hacia fines del siglo XVIII", Antiteses, 4/8 (Londrina, 2011): 753-782.

Real Sociedad Económica Matritense de Amigos del País, Madrid, Imprenta Antonio de Sancha, 1780.

Romitti Acevedo, Carlos, "Los Candioti de Santa Fe no descienden de un supuesto (y probadamente inexistente) primer matrimonio del gobernador Francisco Antonio Candioti”, Revista del Centro de Genealogía de Entre Ríos, 7 (Buenos Aires, 2009): 513-523.

Socolow, Susan, Los mercaderes del Buenos Aires Virreinal: familia y comercio, Buenos Aires, Ediciones de La Flor, 1991.

Souto Mantecón, Matilde, "Los consulados de comercio en Castilla e Indias. Su establecimiento y renovación (1494-1795)", Anuario Mexicano de Historia del Derecho, 2 (México, 1990): 227-250.

Suárez, Teresa y Tornay, María Laura, "Poblaciones, vecinos y fronteras rioplatenses. Santa Fe a fines del siglo XVIII", Anuario de estudios americanos, 60/2 (Sevilla, 2003): 521-555.

Tarragó, Griselda, "Santa Fe en el período tardo-colonial: producción ganadera, estancias y regiones", Anuario de la Escuela de Historia, 17 (Rosario, 1995-96): 217-239.

Tarragó, Griselda, "Las venas de la monarquía: Redes sociales, circulación de recursos y configuraciones territoriales. El Río de la Plata en el siglo XVIII", José María Imízcoz Beunza y Oihane Oliveri Korta (coords.), Economía doméstica y redes sociales en el Antiguo Régimen, Madrid, Sílex Ediciones, 2010: 177-210.

Tarragó, Griselda, "The long kiss of goodbye: Santa Fe and the conflict over the privilege of puerto preciso (1726-1743)", Giuseppe De Luca y Gaetano Sabatini (eds), Growing in the Shadow of an Empire. How Spanish Colonialism Affected Economic Development in Europe and in the World (XVIth-XVIIIth), Milano, Franco Angeli Editore, 2012: 271-284.

Tarragó, Griselda y Areces, Nidia, "Redes mercantiles y sociedad. Santa Fe, siglo XVIII", Anuario de la Escuela de Historia, 18 (Rosario, 1999): 79-98.

Ternavasio, Marcela, Gobernar la Revolución. Poderes en disputa en el Río de la Plata, 1810-1816, Buenos Aires, Siglo XXI, 2007.

Tjarks, Germán, El consulado de Buenos Aires y sus proyecciones en la historia del Río de la Plata, Buenos Aires, Instituto de Historia Argentina Dr. Emilio Ravignani, 1962. 
Torres Sánchez, Rafael, El precio de la guerra. El estado fiscal-militar de Carlos III (1779-1783), Madrid, Marcial Pons, 2013.

Usoz, Javier, "La nueva política Ilustrada y la esfera pública: las introducciones a la economía en el siglo XVIII español", Revista de Estudios Políticos (nueva época), 153 (Madrid, 2011): 11-46.

Verdo, Geneviève, "La guerre constituante: Río de la Plata, 1810-1821”, Revista de Indias, 69/246, (Madrid, 2009): 17-43.

Villacañas Berlanga, José Luis, "Una idea y escritura de la historia en la conciencia nacional del siglo XVIII", Cuadernos dieciochistas, 14 (Salamanca, 2013): 19-57.

Wasserman, Fabio, "La nación como concepto fundamental en los procesos de independencia hispanoamericana (1780-1830)", Humberto Castrillón (comp.), La nación imaginada. Ensayos sobre los proyectos de nación en Colombia y América Latina en el siglo XIX, Cali, Universidad del Valle, 2015: 19-56.

Zamora, Romina, Casa poblada y buen gobierno. Oeconomía católica y servicio personal en Tucumán, Siglo XVIII, Buenos Aires, Prometeo, 2017.

Fecha de recepción: 28 de septiembre de 2019.

Fecha de aceptación: 13 de abril de 2020.

\section{The Buenos Aires Consulate of Commerce and the "Santa Fe Diputación" on the Larramendi Report (1795). Regulations, governability and Enlightenment in eighteenth-century Río de la Plata}

Within the framework of the Bourbon reforms implemented by the Hispanic Monarchy to recover its former splendour, the Consulates of Commerce in the Americas were fundamental instruments in a new rearrangement. This paper analyses the Consulate of Buenos Aires in relation to one of its provincial governments, Santa Fe, on the subject of a text known as the "Larramendi Report" of 1795. It analyses the importance of this document as an expression of the tensions and disagreements that faced the elites of Santa Fe and Buenos Aires, demonstrating that the Consulate brought to light problems that went beyond those envisaged by the Crown that are ultimately evidence of rivalries with Buenos Aires that would deepen in the following century, after the revolutionary wars.

Key words: Enlightenment; Río de la Plata; governance; Bourbon reforms; Diputaciones. 